\title{
The Dark Side of Knowledge
}

\author{
Jan Keitzmann \\ University of Victoria \\ jkietzma@uvic.ca
}

\author{
Hope Jensen Schau \\ University of Arizona \\ hschau@email.arizona.edu
}

\author{
Constantine S. Katsikeas \\ University of Leeds \\ $\underline{\text { C.S.Katsikeas@leeds.ac.uk }}$
}

\begin{abstract}
This introduction overviews the dark side of knowledge management. The aim of this minitrack is to improve understanding of the so far largely neglected dark side of knowledge by encouraging researchers from a variety of fields to share their work. The dark side of knowledge has implications for individuals, communities, organizations and many aspects of society.
\end{abstract}

\section{Introduction}

Information systems of various kinds have been transforming how individuals, communities and organizations create, share and consume information and knowledge with each other and with firms (Kietzmann, Hermkens, McCarthy, \& Silvestre, 2011). At an exciting time of rapid technological advancements (e.g., of AI, cognitive computing), many studies highlight the "bright side" of knowledge and the systems used to manage it. Examples include how social media democratize engagement between firms and consumers or how firms can improve public relations, customer service, product development, or personnel decision making. None of these business activities are imaginable anymore without systems involvement.

Regardless of the numerous opportunities that knowledge and information systems offer, there is undoubtedly a "dark side" that holds enormous risks for individuals, communities, organizations and even whole societies (Baccarella, Wagner, Kietzmann, \& McCarthy, 2018). The recently coined term "surveillance capitalism" (Zuboff, 2019) illustrates how governments and corporations can leverage knowledge and systems to invade privacy (Pai \& Arnott, 2013), use fake news (Allcott \& Gentzkow, 2017; European Commission, 2018) and trolling (Buckels, Trapnell, \& Paulhus, 2014; Hardaker, 2010) to manipulate and deceive. Conversely, others have explored concerns such as cyberbullying (O'Keeffe \& Clarke-Pearson, 2011), addictive use (Blackwell, Leaman, Tramposch, Osborne, \& Liss, 2017), and collective consumer efforts to realize market value unintended by the firm (Campbell and Schau 2019). Beyond issues regarding how individuals and organizations might inappropriately exploit access to knowledge, there is the "curse of knowledge," a cognitive bias that occurs when an informed individual wrongly assumes that others have the background to understand an issue (Heath and Heath, 2006) or is unable to ignore more knowledge (Camerer, Loewenstein, and Weber, 1989). Therefore, despite the many benefits promised, the significant negative or detrimental consequences of knowledge and information systems are worthy of research attention. Further theoretical as well as empirical work is needed to better understand this dark side.

The dark side of knowledge has implications for individuals, communities, organizations and many aspects of society. Potential topics and underlying research questions may include but are not limited to:

- Theories, models and classification frameworks that shed light on the dark side of knowledge.

- Methods for studying the dark side of knowledge and its impact on individuals, communities and organizations, and on many aspects of society.

- Understanding how individuals, communities and organizations can minimize, prevent or respond to the dark side of knowledge.

- Understanding what motivates individuals, communities and organizations to deliberately engage in dark side behaviours and practices.

- Examining dark side outcomes, behaviours and practices that accidently or unintentionally emerge. 
- Approaches to lobbying, regulating and controlling dark side behaviours and practices.

- Region, sector and industry-focused studies on the dark side of knowledge.

- Specific phenomena, including but not limited to surveillance capitalism, fake news, online bullying, conspiracy, hashtag hijacks, reputation blackmail, online firestorms, tweetup disasters, activities on the darknet/dark web/deep web.

The paper selected for this track discusses the implications of buyers and sellers being influenced by the information they receive and how that impacts their decision-making process in the context of a high-value low-frequency transaction (HVLFT). Using an exploratory case study, Hoksbergen and colleagues explore a dark dimension of knowledge where tacit or explicit knowledge has been lost, distorted, suppressed, misrepresented, or misappropriated resulting in ambiguity and increased risk in decision making.

\section{References}

Allcott, H., \& Gentzkow, M. (2017). Social media and fake news in the 2016 election. Journal of Economic Perspectives, 31(2), 211-236.

Baccarella, C. V., Wagner, T. F., Kietzmann, J. H., \& McCarthy, I. P. (2018). "Social media? It's serious! Understanding the dark side of social media." European Management Journal, 36(4), 431-438.

Blackwell, D., Leaman, C., Tramposch, R., Osborne, C., \& Liss, M. (2017). Extraversion, neuroticism, attachment style and fear of missing out as predictors of social media use and addiction. Personality and Individual Differences. Personality and Individual Differences, 116, 69-72.

Buckels, E. E., Trapnell, P. D., \& Paulhus, D. L. (2014). Trolls just want to have fun. Personality and Individual Differences, 67, 97-102.

Camerer, Colin, George Loewenstein, and Martin Weber. "The curse of knowledge in economic settings: An experimental analysis." Journal of political Economy 97, no. 5 (1989): 1232-1254.

Campbell, Colin and Hope Jensen Schau (2019), "Let's Make a "Deal": How Deal Collectives Coproduce Unintended Value from Sales Promotions," Journal of Marketing, 83.6: 43-60.
European Commission. (2018). Final Report of the High Level Expert Group on Fake News and Online Disinformation. Retrieved from https://ec.europa.eu/digital-single-market/en/news/finalreport-high-level-expert-group-fake-news-and-onlinedisinformation Accessed 2018-05-03.

Hardaker, C. (2010). Trolling in asynchronous computer-mediated communication: From user discussions to academic definitions. Journal of Politeness Research, 6(2), 215-242

Heath, C. and Heath, D., 2006. The curse of knowledge. Harvard Business Review, 84(12), pp.20-23.

Hoksbergen, M., Peko, G., Chan, J. and Sundaram, D. Fire in the Records: The Dark Side of Knowledge Management, HICSS 2021

Kietzmann, J. H., Hermkens, K., McCarthy, I. P., \& Silvestre, B. S. (2011). Social media? Get serious! Understanding the functional building blocks of social media. Business Horizons, 54(3), 241-251.

O'Keeffe, G., \& Clarke-Pearson, K. (2011). Clinical report the impact of social media on children, adolescents, and families. Pediatrics, 127, 800-804.

Pai, P., \& Arnott, D. C. (2013). User adoption of social networking sites: Eliciting uses and gratifications through a means-end approach. Computers in Human Behavior, 29(3), 1039-1053.

Zuboff, S. (2019, January). Surveillance Capitalism and the Challenge of Collective Action. In New Labor Forum (p. 1095796018819461). Sage CA: Los Angeles, CA: SAGE Publications. 